\title{
Breaking the Mathematics Phobia of Secondary School Students Using Behaviour Modification Techniques
}

\author{
Onivehu, A.O. \\ Department of Psychology and Education \\ University of Education, Winneba \\ and \\ Ziggah, S.R. \\ Department of psychology and Education \\ University of Education, Winneba
}

\begin{abstract}
A unified approach to learning must specify what kinds of internal processes mediate the influences of diverse internal and external sources and must do so without abandoning crucial mentalistic concepts such as attention, curiosity, interest, motivation and meta-cognition. As our understanding progresses in this area, we may begin to comprehend how very young children can be so effective in learning their functional knowledge of the world and their mastery of school subjects. Teaching should be seen as an activity that is designed and performed for multiple objectives, in terms of changes in student behaviours. Students have multidimensional personalities having different learning styles. The common implication of these facts are that, the teachers should use different strategies of teaching, that is, matching the objectives of teaching and students' learning styles and personality dimensions, but the teacher education programme in Ghana, however, prepare the teachers for one or a few fixed ways of teaching such as the lecture method, the discovery method; inquiry method among others. It is in the light of the above that, this paper examines the use of behaviour method of teaching mathematics to alleviate the Mathematics Phobia among secondary school students.
\end{abstract}

\section{Introduction}

No Nation can attain any technological break through without well planned and effective implementation of a mathematics education, since mathematics plays a leading and service role in all aspects of human endeavour. Therefore, mathematics teaching and learning require a lot of space for demonstrations and self-learning activities to make an educated man. This was buttressed by Griffiths and Howson (1974:163), when they asserted that," the educated man is the knowledgeable man, trained to approach the affairs of his daily life with some sense of detachment and objectivity and to reason about them soberly and correctly".

Mathematics is the means of sharpening the individual's mind, shaping his reasoning ability and developing his personality, hence, its immense contribution to the general and basic education of the people of the world (Asiedu-Addo and Yidana, 2000). A mathematics teacher should therefore provide students with stimulating and wide-range of mathematical learning experiences that will develop their skills and knowledge. This will enable them function as useful citizens. 
Howson and Wilson (1990) asserted that the teacher that lacks workspace cannot develop far as a reflective practitioner. This was buttressed by Franke and Carey (1997) when they commented that, the nature of the classroom environment in which mathematics is taught strongly influences how children perceive the subject, how it should be done and what they consider appropriate responses to mathematical questions. For example, a teacher who has to teach many classes a day has little time to reflect on his or her teaching and or prepare instructional materials for alternative approaches.

In a nutshell, sustainable development in nation building is essential and it is technological advancement of the masses that can lead to its realization in Ghana and in other developing countries. In Ghana, for example, mathematics is a compulsory subject in both the Basic school and senior secondary school curricula.

The compulsory nature of mathematics vis-à-vis the conception of the teacher of mathematics will also go a long way to demystify the phobia surrounding the teaching and learning of mathematics. This was buttressed by Thompson (1984:125) when he asserted that "the observed consistency between the teachers' professed conceptions of mathematics and the way they typically presented the content strongly suggest that the teachers' views, beliefs and preferences about mathematics do influence their instructional practices".

\section{Behaviour Modification}

The term "behaviour", according to Cormier and Hacknney (1993), includes covert or private events such as thoughts, beliefs and feelings (when they can be clearly specified), as well as overt events or behaviours that are observable by others. Developing adaptive behaviour often involves weakening or eliminating behaviours that work against the desired outcome therefore, adaptive behaviours help a person meet biological and social needs and avoid pain and discomfort (Wolpe, 1982). Behaviour modification is a reaction of a body to stimuli, playing down the role of the brain as a processor of information.

Behaviour modifications or interventions involve strategies that focus on skills, actions, habits and behavioural excesses and deficits. They are intended to help students to change their behaviour when that behaviour fails to support their goals, ambitions or values, or when that behaviour contributes to negative outcomes. Behaviour helping strategies utilize theories and processes of learning (Cormier and Hackney, 1993).

Although a large number of strategies can be classified as behaviour in nature and focus, perhaps the most common ones include social modelling approaches, skills training, operant conditioning, and contracting, relaxation training, systematic desensitization, covert conditioning and selfmanagement techniques (Cormier and Cormier, 1985; Rimm and Masters; 1979). Behavioural approaches also share much in common with other 
action oriented approaches to helping, such as reality therapy developed by Glasser (1965). Glasser and Zunin (1979) noted that, changes in behaviour that occur from reality therapy strategies also involved learning. They commented that "we are what we do, and to a great extent, we are what we learn to do, and our identity becomes the integration of all learned and unlearned behaviour.

Behavioural interventions share certain common elements with the following:

1. Maladaptive behaviour (that which produces undesirable personal or social consequences) is the result of learning, not illness, disease, or intrapsychic conflict.

2. Maladaptive behaviours can be weakened or eliminated, and adaptive behaviour can be strengthened or increased through the use of psychological principles, especially principles of learning that enjoy some degree of empirical support.

3. Behaviour (adaptive or maladaptive) occurs in specific situations and is functionally related to specific events that both precede and follow these situations. For example, a student may be aggressive in some situations, without being aggressive in other situations. Thus, behavioural practitioners attempt to avoid labeling students using arbitrary descriptors like "aggressive". Instead, emphasis must be placed on what a student does or does not do that is "aggressive" and what situational event precipitates the aggressive response, as well as events that strengthen or weaken the aggressive responses.

4. Clearly defined outline or treatment goals are important for the overall efficiency of these interventions and defined individually for each student. Thus, teachers must attempt to avoid projecting their desires for change onto students and also help students specify precise outcomes they want to make as a result of their teaching.

5. Helping interventions must focus on the present rather than the past or future and must be selected and adapted for each student on his or her set of problems and concerns. Behavioural approaches reject the "all purpose teaching" notion that assumes that, one method, or approach is generally appropriate for most students.

\section{What is Phobia or Phobic Reaction?}

Phobia refers to fear of an object or a particular situation that may be harmless. Phobic reactions are the acts exhibited as a result of an encounter with the fear arousing object or situation. Examples are anxiety, depression and stress.

Anxiety is a state of feeling nervous or worried that something bad is going to happen. For example, a person who suffers from anxiety neuroses has a fear or worry that has no basis. Such a person shows too much concern for his or her future to the extent that they are easily upset when the least mistakes are committed.

Depression is a condition where the person feels uncomfortable and unhappy. He or she may prefer to be alone and not mix in social 
activities, he or she may not be able to concentrate on their studies. He or she feels a sense of unworthiness and questions his or her cause of living.

Stress means stimuli that are likely to produce disturbance in most individual. A stressful person may not be able to release tension adequately and this may lead to emotional disturbances.

\section{Using Behaviour Modification Techniques in Teaching Mathematics}

Skinner (1969) asserted that good teaching is the ability to arrange proper sequences of reinforcements for the students. Bruner (1966) also insists that, the final goal of teaching is to promote the "general understanding of the structure of a subject". That is, when the student understands the structure of a subject, he or she sees it as a related whole. "Grasping the structure of a subject is understanding it in a way that permits many other things to be related to it meaningfully". Bruner further stated that, when learning is based on a structure, it is more long-lasting and less easily forgotten. This is what Bruner calls a "teacher prescriptive theory of instruction", because it prescribes in advance how a given subject can best be taught. For example, if a learning theory tells us that, children at age six are not yet ready to understand the concept of reversibility, a theory of instruction would prescribe how best to lead the child towards this concept when he or she is old enough to understand it.

Teaching methods, according to Siddiqui and Khan, (1991), inevitably constitute significant aspects of the human effort to educate. These are, the patterns of teachers behaviour that recurrent applicable to various subject matters, characteristics of more than one teacher and relevant to learning and may be considered a sub-category of educational methods. This includes instructional devices such as teaching machines, conventional and programmed textbooks, simulations, films and others such as, inductive and deductive methods, heuristic method, lecture method, discussion method, discovery method, problem-solving method and project method among others.

\section{Models of Teaching}

Bruice and Marsha (1985) define models of teaching as a plan or pattern that can be used to shape curricula, to design instructional materials and to guide instruction in the classroom and other settings. The most important aim of any model of teaching is to improve the instructional effectiveness in an interactive atmosphere and to improve or shape the curriculum. Despite the insightful psychological and learning theories of Piaget (1958), Bruner (1966), Gagne (1970) and Skemp (1976) the learning of mathematics is still far from satisfaction. Begle and Gibb (1980) observed that while psychology has provided us with general theories of learning, we have not established general theory of learning mathematics to provide a basis for mathematics education. Researchers have revealed the under-achievement in mathematics by significantly large numbers of children in many countries [Husen (1967); Carpenter, Coburn, Reys and Wilson (1978); Cockcroft, (1982) and (Eshun, (1999)]. 
Therefore, the task for research in mathematics education is to provide information that would help "to understand better how, where, and why people learn or do not learn mathematics" (Begle and Gibb, 1980:8). However, the determinants that affect the learning of mathematics include; the learner's intellectual ability, maturity, learning style, emotional and social adjustment as well as attitudes.

People develop attitudinal behaviours towards mathematics just as they develop attitudes towards people, politics, religion, institutions and school subjects. Allport's (1935) definition of attitude implies that attitude is a state of an individual's mind that has resulted through experience and directs how that individual should respond to an object or situation that is related to or associated with it. On the other hand, Rokeach's (1972) definition implies that, attitude is the result of several beliefs a person hold that make him or her respond in a preferential way towards an object or situation. Staats' (1981) definition agrees in principle with Allport's (1935), that, attitude is not innate, it is a learned disposition and therefore could be changed and it permits response to things in some way. The objects or situations in all the above definitions may be mathematics itself, solving mathematics problems, understanding concepts in mathematics, usefulness of mathematics or motivation for learning mathematics. Therefore, attitude towards mathematics is a disposition towards an aspect of mathematics that has been acquired by and individual through his or her beliefs and experiences but which could be changed.

Howson and Wilson, (1990), points out that the teacher that lacks workspace cannot develop far as "a reflective practitioner". This was buttressed by Franke and Carey (1997) when they asserted that the nature of the classroom environment in which mathematics is taught strongly influences how children perceive the subject, how it should be done and what they consider appropriate responses to mathematical question.

Mathematics anxiety manifests itself in persons who are uncomfortable in the world of representative samples and data analysis. Widmer and Chavez (1982) asked, What lies at the root of strong negative feelings about things mathematical?" The exact philosophy of causation may never be known, but several factors play a role. These factors include

a lack of preparedness,

b conditioning of associations, and

c expectations of teachers and students.

To avoid phobia among students as far as teaching mathematics is concerned, learning in the classroom should be transferable since transfer is the key to learning. Sprinthall and Sprinthall (1990) asserted that, transfer takes place when learning task " $\mathrm{A}$ " influences learning task "B". For example, teaching addition in mathematics before subtraction and division. Thus, when learning " $\mathrm{A}$ " facilitates learning " $\mathrm{B}$ ", positive transfer is said to have taken place ; conversely, when learning " $\mathrm{A}$ " inhibits learning " $\mathrm{B}$ ", negative transfer has occurred. 
In view of the theories and the assertions by scholars as regards the breaking down of the myth surrounding the learning of mathematics among secondary students, Bruice and Marsha (1985) developed models of teaching to curb the phobia among students as far as mathematics teaching and learning in senior secondary schools is concerned. Bruice and Marsha (1985) organised the alternative models of teaching mathematics into four families, these are information processing, personal, social and behavioural. They stressed that the different instructional goals in mathematics would be realized by putting these models of teaching into action.

\section{Information Processing Family of Models of Teaching}

The models of teaching of this family are concerned with the organisation, presentation of verbal and non-verbal symbols in a way that helps in the formation of concept and solution problem and development of social relationship and integrated personality. Thus, these models are concerned with the productive thinking and development of general intellectual ability. The important models associated with this family are as follows.:

a Inductive Thinking Model of Hilda Taba: process the information through inductive "process".

b. Scientific Inquiry Model of Schwab: This model is designed to teach the method employed by the subject for solving scientific and social problems.

c. Concept Attainment Model of Bruner: This concept develops inductive reasoning that is, developing a concept after presenting its examples and non-examples.

d. Advance Organizer Model of David Ausubel: This model increases the capacity of learner to absorb and relate bodies of knowledge.

e. Cognitive Growth Model of Jean Piaget: This has been designed to increase general intellectual ability especially logical reasoning.

f. Memory Model of Herry Lorayne: This model is designed to increase the capacity to memorise concepts, facts among others (Siddiqui and Khan, 1991).

\section{Personal (Family of) Models of Teaching}

The models of this family is intended to develop the unique personality of the learner. These models pay more attention to the emotional life of the person and also focus on helping individuals to develop a productive relationship with their environment. Some of the important models of this family are as follows:

a. Non-Directive Teaching Model of Karl Rogers: This model aims at the development of the personal self in self-awareness, autonomy and self-concept.

b Synectics Model of William Gorden: This model is designed to develop creativity and creative problem solving in the learner.

c Classroom Meeting Model of William Glasser: The model aims at the development of a sense of responsibility and self-confidence in one's social group.

\section{Social (Family of) Models of Teaching:}


The models of this family are concerned with the social relationship of the individual with others in the society/classroom. These models aim at the development of social relationship, democratic processes and work productivity in the society. These models restrict themselves to the development of social relationship. They are also concerned with the development of mind, and the learning of academic subjects. Some important models of this family are as follows;

a. Group Investigation Model of Herbert Thelen and John Dewey: This model aims at the development of skills for participation in democratic social processes through interaction skills and inquiry skills.

b. Role Playing Model of Shaftel and Shaftel: It aims at motivating students to inquire into different personal and social values.

c. Social Simulation Model of Seren Boocock and Harold Guitzknow: This model is designed to help students to experience various social processes and to examine their own reaction to them and also acquire concept and decision making skills. (Siddiqui and Khan, 1991).

\section{Behavioural (Family of) Models of Teaching:}

The main thrust of these models is modification of the visible or overt behaviour, as well as the underlying psychological structure and unobservable behaviour of the learner. The main psychological bases of these models are stimulus control and reinforcement as put forward in B.F. Skinner's theory of operant conditioning and Bandura's theory of social learning. The common characteristic of these models are that, they break down the learning task into series of small sequences of behaviour. Each behaviour is so designed that success is ensured; the learner actively responds to the problematic situation and gets reinforcement and feedback. Some of the important models of this family are as follows:

a. Contingency Management Model of B.F. Skinner. This model proposes to teach facts, concepts, and skills to the learners by the teacher.

b. Self-Control Model of B.F. Skinner. It is designed to develop social behaviour and social skills among learners.

c. Stress Reduction Model of Rimm and Masters. This model aims at reduction of stress and anxiety in social situation and their substitution by relaxation among students.

d. Desensitization Model of Walpe. It is a model designed to reduce anxiety through pairing deep muscles relaxation with imaginative scenes that the student had said cause him or her to feel tense.

The above mentioned models under different aspects of human personality that is, the social, personal, informational and behavioural. Since education is meant for all round development of a child's personality, no single model can be selected for his or her development. Therefore, for effective teaching of mathematics in our senior secondary schools and its subsequent elimination of phobia among students, all the models will have to be employed according to the requirements of the situation, that is, if some 
information is to be given, models of the first family would be required; if creativity is to be developed in the child, synectic model would be needed; if the objective is to eliminate anxiety and stress, desensitization model of Walpe would be needed, and if the objective is the development of the social skill, then model like Group Investigation Model of Herbert Thelen would be required (Siddiqui and Khan, 1991).

Furthermore, the selection of model also can be dependent on curriculum requirement, for example, a biology teacher may need the inductive model of Hilda Taba and Concept Attainment Model of Bruner, and social studies teacher who proposes to teach about values would need Role Play Model of Fannie Shaftel and George Shaftel, which motivates students to inquire into personal and social values.

However, some situations would require an application of a combination of models, that is, in a social studies class, the teacher may use Inductive Thinking Model to help children master map skills and Group Investigation Model for criticizing social issues.

As already mentioned, mathematics plays a leading service role in all aspects of human endeavour and ensuring a smooth mathematics education programme requires the formulation and implementation of appropriate instructional policies. For instance, a mathematics curriculum should therefore, provide children with stimulating and wide range of mathematical learning experiences that will develop their skills and knowledge. This will enable them function as useful citizens.

An intended mathematics curriculum should consist of a description of all the mathematical activities that children have to experience throughout their period of schooling to achieve certain objectives. This support earlier work of researchers such as Gibson 1969; Carmichael, Hogan and Walter, 1932; Zangwill, 1937; Krechevsky, 1938; Mowrer, 1947; Hebb, 1961) when they emphasized that perception is affected by past experience.

This fact, was also buttressed by Hebb (1961) when he asserted that, there is a behavioural evidence on the relationship between learning in infancy and that of the normal adult. Here, it is proposed that, the characteristics of the learning undergo forms of an important change as the animal grows; particularly in the higher mammals. That, all learning tends to utilize and build on any earlier learning instead of replacing it thus, much early learning tends to be permanent (Mowrer, 1947).

It is a truism that learning is often influenced by earlier learning experience since innumerable experiments have shown such a "transfer of training " that is, learning ' $\mathrm{A}$ ' may be speeded up, hindered or qualitatively changed by having learned before, hence to eliminate phobia among students, mathematics teachers should encourage classroom discourse that is appropriately balanced between elicit, inform, direct and feedback exchanges and also use contexts that present real life experiences of the mathematical concepts and skills being taught (Mereku, 1995). This then, brings into focus the use of behavioural modification techniques in teaching mathematics. 


\section{References}

Allport, G.W. (1935). "Attitudes". In C. Murchison (Ed). A handbook of Social Psychology, Worcester: Mass Clark University Press.

Aseidu-Addo, S.K. and Yidana I, (2000). "Mathematics Teachers Knowledge of the subject Content and the Methodology". Journal of the Mathematical Association of Ghana, Volume 12, University of Cape Coast. MAG Secretariat.

Begle, E.G. and Gibb, E.G. (1980), Why do research" Research in Mathematics Education. National Council of Teachers of Mathematics.

Bruner, J.S. (1966). Toward a Theory of Instruction. Cambridge, Massachusetts Belknap Press.

Cockcroft, W.H. (1982). Mathematics Counts. HMSO, London.

Chavez, A. and Wildmer, C. (1982). "Math Anxiety: Elementary Teachers Speak for Themselves". Educational Leadership (39:387-88).

Eshun, B.A. (1990). "Sex - related Differences in Mathematics achievement of Secondary School Students" - An Unpublished paper. University of Cape Coast.

Grifiths, A.H.B. and Howson, A.G. (1974). Mathematics Society of Curricula. London, Cambridge University Press.

Howson, G. and Wilson, B. (1990). 'School Mathematics in the 1990s' (A.G. Howson and J.P. Kahane eds). ICMI Study Series, Cambridge: Cambridge University Press.

Joyce, Bruice, and Weil Marsha, (1985). "Models of Teaching" New Delhi: Printice Hall limited.

Mereku, K. D. (1995). "A Comparison of the official Primary Mathematics Curriculum in Ghana with the way in which it is implemented by teachers". University of Leeds: School of Education (PhD. Dissertation).

Piaget, J. (1958). The Growth of Logical Thinking from Childhood to Adolescence, New York: Basic Books.

Siddiqui, M.H. and Khan, M.S. (1991). Models of Teaching. (Theory and Research) New Delhi: Ashish Publishing House.

Skemp, R.R. (1973). The Psychology of Learning Mathematics. Baltimore MD: Penguin Books Inc.

Skinner, B.F. (1969). "Why Teachers fail": Educational Psychology, New York, Van Nostrand - Reinhold. (164-172).

Sprinthall, N.A.and Sprinthall, R.C. (1990). Educational Psychology - A Development Approach (5 $5^{\text {th }}$ edition). USA: McGraw Hill, Incorporated.

Staats, (1981). An Outline of an Integrated Learning Theory of Attitude. New York Wiley. 